\title{
The role of the observed tropical convection in the generation of frost events in the southern cone of South America
}

\author{
G. V. Müller ${ }^{1}$, T. Ambrizzi ${ }^{2}$, and S. E. Ferraz ${ }^{3}$ \\ ${ }^{1}$ Centro de Investigación Científica y de Transferencia Tecnológica a la Producción (CICYTTP/CONICET), Diamante, \\ Argentina \\ ${ }^{2}$ Departamento de Ciências Atmosféricas, Universidade de São Paulo, Brazil \\ ${ }^{3}$ Departamento de Física, Universidade Federal de Santa Maria/CRSPE-INPE, Brazil
}

Received: 4 September 2007 - Revised: 3 March 2008 - Accepted: 3 April 2008 - Published: 11 June 2008

\begin{abstract}
Based on previous results obtained from observations and linear wave theory analysis, the hypothesis that large-scale patterns can generate extreme cold events in southeast South America through the propagation of remotely excited Rossby waves was already suggested. This work will confirm these findings and extend their analysis through a series of numerical experiments using a primitive equation model where waves are excited by a thermal forcing situated in positions chosen according to observed convection anomalies over the equatorial region. The basic state used for these experiments is a composite of austral winters with maximum and minimum frequency of occurrence of generalized frosts that can affect a large area known as the Wet Pampas located in the central and eastern part of Argentina.

The results suggest that stationary Rossby waves may be one important mechanism linking anomalous tropical convection with the extreme cold events in the Wet Pampas. The combination of tropical convection and a specific basic state can generate the right environment to guide the Rossby waves trigged by the tropical forcing towards South America. Depending on the phase of the waves entering the South American continent, they can favour the advection of anomalous wind at low levels from the south carrying cold and dry air over the whole southern extreme of the continent, producing a generalized frost in the Wet Pampa region. On the other hand, when a basic state based on the composites of minimum frosts is used, an anomalous anticyclone over the southern part of the continent generates a circulation with a south-southeast wind which brings maritime air and therefore humidity over the Wet Pampas region, creating negative temperature anomalies only over the northeastern part
\end{abstract}

Correspondence to: G. V. Müller

(gabrielamuller@cicyttp.org.ar) of the region. Under these conditions even if frosts occur they would not be generalized, as observed for the other basic state with maximum frequency of occurrence of generalized frosts.

Keywords. Meteorology and atmospheric dynamics (Climatology; General circulation; Middle atmosphere dynamics)

\section{Introduction}

During the past decades many observational and numerical works have shown how tropical thermal forcings can affect the atmospheric circulation. The relation that exists between the anomalous tropical heating and the circulation patterns in the extratropics explains a significant fraction of the flow variability in middle latitudes. In particular, for the Southern Hemisphere, some studies like the ones carried out by Nogues-Paegle and Mo (1988), Berbery and Nogues-Paegle (1993), Mo and Higgins (1998), demonstrated the influence of the tropical heating on the subtropical and extratropical circulation in the intraseasonal time scale. The interaction between tropical convection and global circulation can occur through the dispersion of Rossby waves which propagate to the extratropics. The propagation of these waves is essentially dependent on the structure on the basic state and the heat source (Ambrizzi et al., 1995, and references therein). This mechanism, known as the tropic-extratropic interaction, modifies the structure of the higher latitude mean flow modulating the characteristics of the synoptic systems.

Considering a basic state formed by winters with a maximum frequency of occurrence of extreme cold events - frosts -, the associated patterns of a Rossby wave which can cause temperature decrease in the central-eastern Argentina region,

Published by Copernicus Publications on behalf of the European Geosciences Union. 
will be studied here. This region is of great importance for the Argentinean economy, since it is the main agriculture production region with an approximate area of $3 / 4$ million $\mathrm{km}^{2}$ and that continues to expand.

\subsection{Frosts in the Wet Pampas}

Frosts, defined as those days during which surface temperature is equal to or less than $0^{\circ} \mathrm{C}$, are divided into three groups: isolated, partial and generalized. According to the criterion defined by Müller et al. (2000), each day is classified as: isolated frost when the percentage of stations with frost in the Wet Pampas is equal to or less than $25 \%$ of the total; partial frost (PF) when it is between $25 \%$ and $75 \%$ and generalized frost (GF) when the percentage is equal to or more than $75 \%$ (details of the criteria is in Müller, 2006). The analysis of frosts in the region shows great interannual and interseasonal variability in their frequency of occurrence (Müller, 2006). Therefore, to understand the large-scale atmospheric circulation associated with cold episodes, those years with an extreme frequency of frost occurrence which affect a great part of the Wet Pampas were isolated. The different groups (GF, $\mathrm{PF}+\mathrm{GF}$ - partial+generalized frost - and PF) are selected for those periods where the number of frosts is one standard deviation unit below $(-\sigma)$ and above $(+\sigma)$ of the mean value for the period 1961-1990. Following these criterion, the extremes in the frequency of frost occurrence are identified for the groups GF (Müller et al., 2005), PF+GF and PF (Müller, 2007), in the same 30-year period.

1.2 Hypothesis on the origin of generalized frosts in the Wet Pampas

One of the results which comes out of the analysis of the atmospheric circulation for these groups mentioned, is related to the intensification (weakening) of the South American subtropical jet stream, particularly for the austral winters with $+\sigma(-\sigma)$, which means anomalies at upper levels of the prevailing westerly (easterly) wind for GF $+\sigma(-\sigma)$, $\mathrm{PF}+\mathrm{GF}+\sigma(-\sigma)$ and $\mathrm{PF}+\sigma(-\sigma)$, demonstrated by Müller et al. (2005) and Müller (2007), respectively. Additionally, Müller et al. (2005) compared the atmospheric circulation fields during GF $+\sigma(-\sigma)$ with the composites of anomalous cold winters AC (warm winters, AW). The GF $-\sigma$ and the AW winters have negative wind anomaly in the South American subtropical jet region, indicating a prevalence of flow from the east. The weakening of the jet during the winter may suggest some dynamic process changes in the maintenance of the jet which could be associated with the reduction of extensive frosts in southern South America or over a complete absence during some winters. Further, Müller et al. (2005) showed that during AC winters, the jet extends eastwards covering a large region over the continent and with a maximum greater than the one observed in $\mathrm{GF}+\sigma$. Although the South American subtropical jet is also intensified during $\mathrm{AC}$ winters, the $\mathrm{GF}+\sigma$ group is characterized by the presence of a wind anomaly which is confined in extension and centered over the Andes (see their Fig. 3). The difference between both groups could be due to different mechanisms acting to intensify the subtropical jet.

Two possible mechanisms that could intensify the South American subtropical jet are i) the anomalous meridional transport of the zonal momentum through the establishment of a Hadley cell and ii) the excitement of Rossby waves which alter the flow at high levels to accelerate the jet (Antico, 2003). AC winters could happen because of an increase in the Hadley cell circulation due to an anomalous SST heating observed in the eastern equatorial Pacific, as shown by Müller et al. (2005). When this heating takes place the tropical convection is intensified and consequently the Hadley cell is strengthened. In contrast, when the sea surface is cooled, convection is reduced and the Hadley circulation weakens, which probably occurs during GF $+\sigma$ winters, as obtained in the composites of SST anomalies by Müller et al. (2005). In this case the physical mechanism would be given by an increase in Rossby wave activity which reaches the South American continent (mechanism ii). This is supported by the mean pattern of the anomalies of the stream function obtained by Müller et al. (2005), where the presence of stationary waves perturbs the atmospheric circulation intensifying and accelerating the jet through the increase in the gradient in the pressure field observed to the northwest of Argentina. The same authors show that this mean anomaly pattern is not present during AC winters.

Based on the above results the hypothesis of this study is that large-scale patterns may contribute to generate extreme cold events in the Wet Pampas through the propagation of Rossby waves remotely excited. A convection source positioned on the equatorial side of the subtropical jet, i.e. at tropical latitudes, may be the forcing to excite such waves (as demonstrated, for example, by Sardeshmukh and Hoskins, 1988). This heating source generates an upper level divergent flow which moves southwards crossing a region with a strong absolute vorticity gradient due to the presence of the subtropical jet. This strong absolute vorticity gradient region acts as a Rossby wave source forcing the movement to become wave-like, in order to conserve total vorticity. A similar mechanism was discussed in Müller and Ambrizzi (2007), in order to explain the most intense and persistent (2day persistent or higher persistent events) GF events as identified by Müller and Berri (2007), as well as of more frequent GF events as shown by the results of Müller et al. (2005). They are generated over the western tropical Indian Ocean in a mean flow characterized by a zonal wind meridional gradient.

In this sense, through simulations with an Intermediate Global Circulation Model-IGCM (Sect. 2.1) the tropicextratropic relation is investigated by examining the propagation of Rossby waves generated by differential heating observed in the tropical region (Sect. 3.1). Results obtained for 
Table 1. Events selected from $+\sigma$ winters (JJA) (adapted from Müller et al., 2005).

\begin{tabular}{lccccc}
\hline \multicolumn{5}{c}{ GF dates } \\
\hline & 24 Jun 1970 & 7 Jul 1970 & 8 Aug 1970 & 25 Aug 1970 & \\
& 11 Jun 1976 & 26 Jun 1976 & 4 Jul 1976 & 14 Aug 1976 & \\
1 Jun 1988 & 14 Jun 1988 & 24 Jun 1988 & 5 Jul 1988 & 24 Jul 1988 & 26 Aug 1988 \\
\hline
\end{tabular}

basic states GF $+\sigma$ and GF $-\sigma$ are compared in Sect. 3.2. Correlation analyses of some meteorological variables averaged over the Wet Pampa region and the entire globe are shown in the Sect. 3.3. The discussion on the role of tropical convection in the generation of generalized frosts in the Wet Pampas is given in Sect. 4.

\section{Data and methodology}

\subsection{Numerical features}

The numerical simulations presented below were carried out using a baroclinic model (IGCM - Intermediate Global Circulation Model), which is a good tool to analyze the physical mechanisms of planetary wave propagation patterns generated by a simple heating source (e.g. Ambrizzi and Hoskins, 1997). As a basic state the model needs geopotential height, zonal and meridional wind and temperature at 12 vertical sigma levels. The IGCM has global domain, spectrally truncated with a total zonal wave number 42 (T42), includes horizontal and vertical diffusion and Newtonian cooling (Jin and Hoskins, 1995).

The model uses a heating source with an elliptical horizontal structure and fixed position (latitude and longitude). The vertical heating profile follows a cosine function with the maximum amplitude at $400 \mathrm{hPa}$ corresponding to a $5^{\circ} \mathrm{C} /$ day and decaying to zero at the top and surface. This value is equivalent to a latent heat release associated with $10 \mathrm{~mm}$ of precipitation. Although one may question the realism of this heating source, its role here is purely as a Rossby wavemaker.

The basic states GF $+\sigma$ and GF $-\sigma$ (henceforth $+\sigma$ and $-\sigma)$ are forced by a heat source which simulates observed convection in the composites of the $+\sigma$ austral winters and which is determined by outgoing longwave radiation (OLR) anomalies with respect to the 1974-1996 mean values.

\subsection{Observational features}

The basic state of maximum (minimum) frequency of occurrence of generalized frosts is composed of $+\sigma$ winters (JuneJuly-August) given by years 1970,1976 and 1988 ( $-\sigma$ winters for the years 1968, 1973, 1982, 1986) following the criterion adopted by Müller et al. (2005).

In order to better understand the relationship between the frost events over the Wet Pampa and the general circulation associated with them, a linear correlation was applied. The surface mean temperature over the Wet Pampa $\left(27^{\circ} \mathrm{S}-40^{\circ} \mathrm{S}\right.$ and $65^{\circ} \mathrm{W}-57^{\circ} \mathrm{W}$ ) for the GF dates was correlated with the global meridional wind at $250 \mathrm{hPa}$. Also, the mean meridional wind at 850 and $250 \mathrm{hPa}$ over the Wet Pampa area for the GF dates (Table 1) were correlated with the upper and lower levels of the mean global meridional wind. A T-student test was applied in all correlations with a significant level of $95 \%$.

The data used for the model simulation and observed analysis was taken from the NCEP/NCAR Reanalysis Project, available on a $2.5^{\circ} \times 2.5^{\circ}$ resolution grid and was provided by NOAA-CIRES. The surface temperature data are the same as those used by Müller et al. (2000) in their original GF classification.

\section{Results}

\subsection{Tropical convection forcing Rossby waves}

During winter, tropical convection regions are mainly confined to the Intertropical Convergence Zone (ITCZ), the equatorial region and southeastern Asia, due to the presence of the monsoon. At the same time, convection in the South Pacific Convergence Zone (SPCZ) is strengthened. These areas constitute an important wavemaker source. The convective areas can be used as a thermal forcing proxy for the numerical model. The anomalous convection areas, and consequently the position of the heat source are identified through the observed outgoing longwave radiation (OLR) in the basic state that compose the extreme $+\sigma$ and $-\sigma$ winters, assuming that values below $240 \mathrm{~W} \mathrm{~m}^{-2}$ are generally associated with the development of deep convective activity (Liebmann and Smith, 1996).

Figure 1 presents the composites of OLR anomalies during winters with a maximum and minimum frequency of occurrence of generalized frosts. The $+\sigma$ field (Fig. 1a) shows two main regions of anomalous tropical convection in the Southern Hemisphere which are situated in the Indian and western Pacific oceans, respectively, with significant values. It is interesting to point out that this configuration is coincident with the second EOF (Empirical Orthogonal Function) mode of winter OLR anomalies found by Mo and Higgins (1998). The authors associated the OLR EOF modes with two PSA 

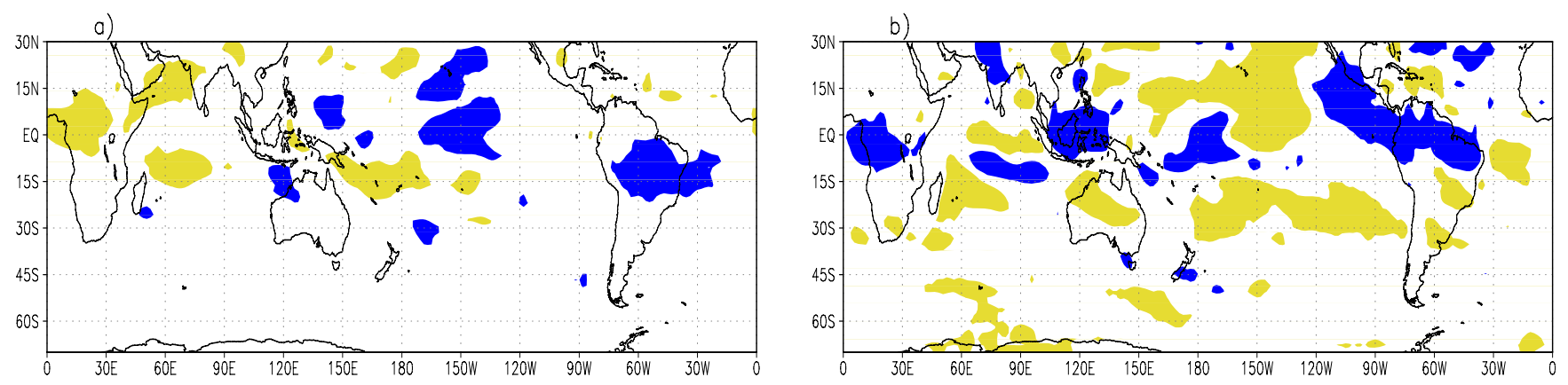

Fig. 1. OLR anomalies $\left(\mathrm{W} \mathrm{m}^{-2}\right)$ for the GF winters of (a) $+\sigma$ and $(\mathbf{b})-\sigma$. Light (dark) shade indicates values smaller than $-6 \mathrm{~W} \mathrm{~m}^{-2}$ $\left(+6 \mathrm{~W} \mathrm{~m}^{-2}\right)$ for $(\mathrm{a})$ and $-3 \mathrm{~W} \mathrm{~m}^{-2}\left(+3 \mathrm{~W} \mathrm{~m}^{-2}\right)$ for (b).
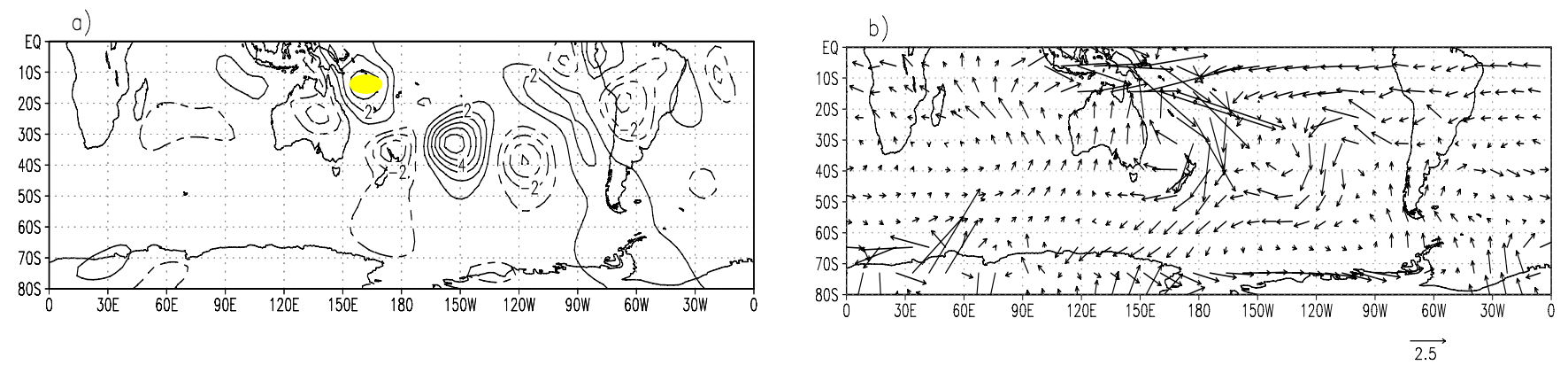

Fig. 2. (a) Meridional wind component anomalies $\left(\mathrm{ms}^{-1}\right)$ on day 10 of integration at $250 \mathrm{hPa}$ and (b) wind vector anomaly at $850 \mathrm{hPa}$, corresponding to the $+\sigma$ basic state experiment with the forcing at $170^{\circ} \mathrm{E}-15^{\circ} \mathrm{S}$.

(Pacific South American) patterns and showed that the composites of OLR anomalies during the mature phases of PSA are similar to the first two EOF modes of the OLR anomalies in the tropics. These modes show an anomalous convection zone in the Pacific Ocean south of the equator $\left(160^{\circ} \mathrm{E}-\right.$ $150^{\circ} \mathrm{W}$ ), and a second area in the western Pacific Ocean with a maximum north of the equator, which represents a suppression of convection. In addition, two minor areas are found in the sub-equatorial latitudes with statistically significant OLR anomaly values, one positive to the north of Australia and the other one negative in the central Indian Ocean. The configuration related to the second EOF mode of OLR anomalies from Mo and Higgins (1998), is similar to the one presented in Fig. 1a for the $+\sigma$ case. On the other hand, in the $-\sigma$ winter composites (Fig. 1b) there are regions with negative OLR anomalies in the Southern Hemisphere, although they do not reach the $240 \mathrm{~W} \mathrm{~m}^{-2}$ threshold.

Theory shows that, the response to the tropical heating is baroclinic in the vicinity of the forcing and barotropic far from the source (Ambrizzi and Hoskins, 1997). This can be seen through vertical cross-section analysis for a given latitude. Our numerical results indicated that the response to the heating source placed in the different latitudes and longitudes showed an equivalent barotropic Rossby wave for the $+\sigma$ and $-\sigma$ basic states and no baroclinic instability development during the 14-day integration period (figures not shown).

\subsection{Numerical simulations with the IGCM model}

\subsubsection{Experiments with $+\sigma$ and $-\sigma$ basic states}

The hypothesis previously stated about the tropicextratropics teleconnection which favors a higher frequency of GF occurrence during $+\sigma$ winters is tested through different numerical simulations. The result of the experiment for the basic state $+\sigma$ and the heat source localized on the position where the anomalous convection is observed in the tropical Pacific, around $170^{\circ} \mathrm{E}-15^{\circ} \mathrm{S}$, is shown by the meridional wind anomaly field at $250 \mathrm{hPa}$ (Fig. 2a). A Rossby wave propagation pattern is observed in this experiment, showing an arc trajectory which was initially directed polewards, deviating towards the equator later on. This result is in agreement with the Rossby wave propagation theory through the calculation of the trajectories applying the ray-tracing technique, as in Müller and Ambrizzi (2006). The OLR anomaly in the western tropical Pacific Ocean, used in the present numerical experiment, is considered as the starting point for different wave numbers. Figure $2 b$ shows that when the wave train reaches South America it creates a southern wind anomaly over the southern continent cone. The extended positive meridional wind anomaly to the southwest of the continent (Fig. 2a) agrees with the anomalous southern flow observed. In the observational analysis where GF events were put together according to 

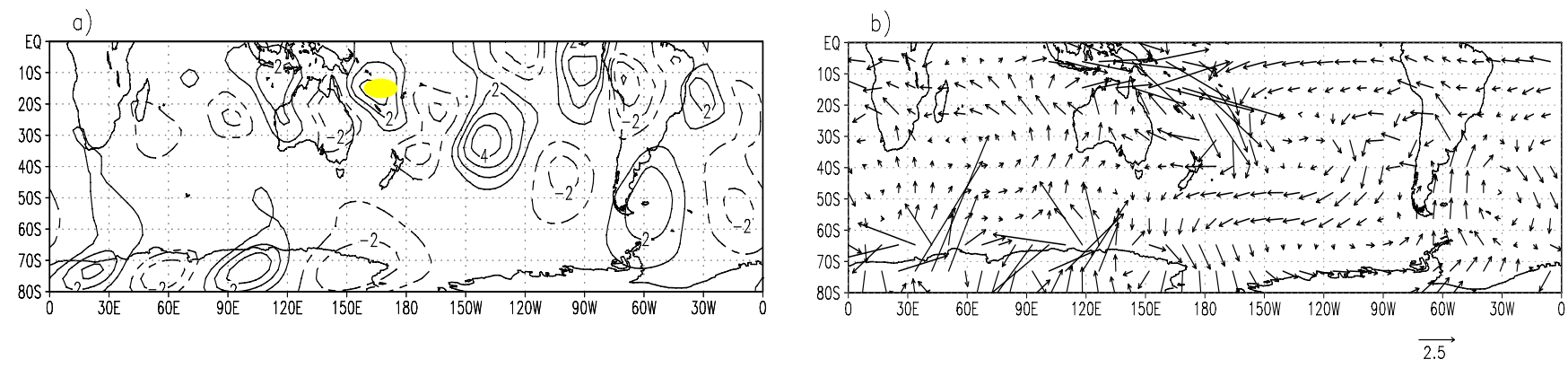

Fig. 3. The same as Fig. 2 but using $-\sigma$ basic state.
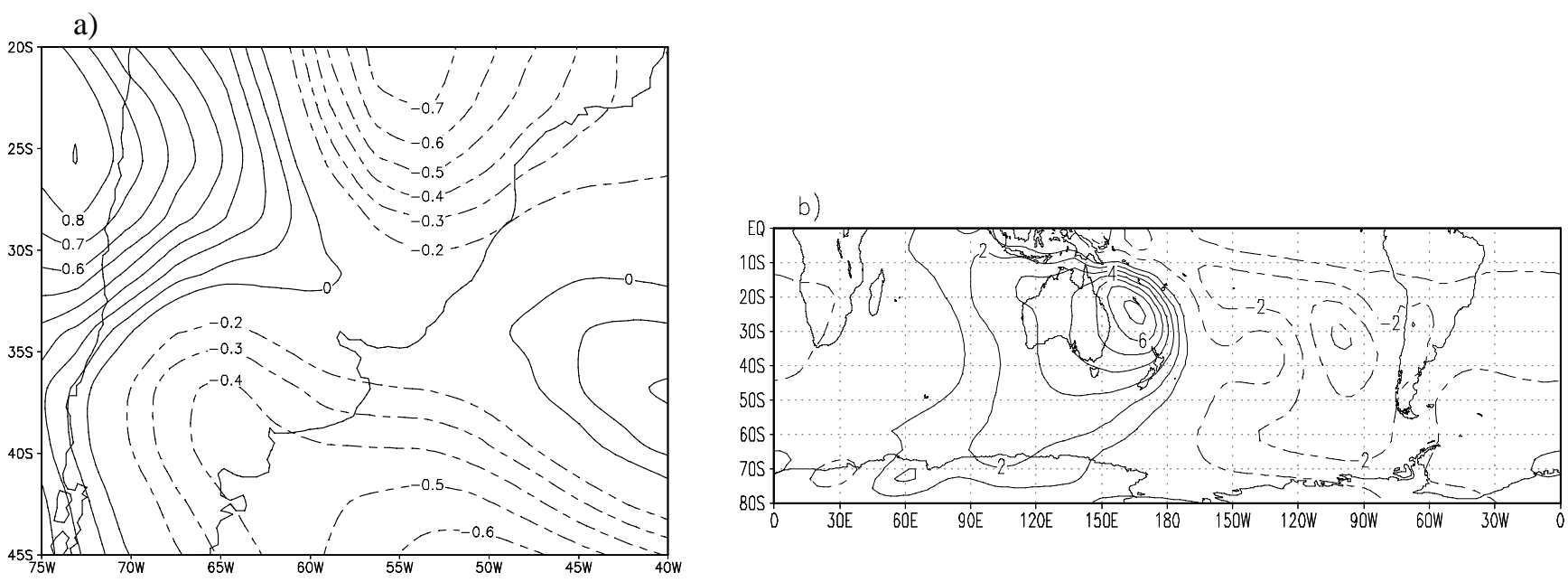

Fig. 4. (a) Surface temperature anomalies $\left({ }^{\circ} \mathrm{C}\right)$ and (b) stream function anomalies $\left(1 \times 10^{-6} \mathrm{~m}^{2} \mathrm{~s}^{-1}\right)$ at $850 \mathrm{hPa}$ on day 10 of integration, corresponding to $+\sigma$ basic state with forcing at $170^{\circ} \mathrm{E}-15^{\circ} \mathrm{S}$.

their persistence Müller and Berri (2007) found a wave propagation pattern very similar to that observed in Fig. 2a for the GF events with a 1-day persistence, i.e. an arc-like propagation with the wave train starting in the central-eastern Pacific Ocean and propagating across the mid-latitude of the Southern Hemisphere. When it reached the South American continent, the wave turned to the northeast, affecting the entire southern cone of South America. This pattern has been associated in the literature with cold surges in South America (e.g. Marengo et al., 1997, 2002; Cavalcanti and Kayano, 1999; Garreaud, 2000).

On the other hand, it is interesting to compare the wave pattern trajectory obtained in this experiment with the stationary wave number field $\left(K_{S}\right)$, shown in Müller and Ambrizzi (2007). According to the linear wave theory, the characteristics of the Rossby wave propagation in a given basic state may be determined by the analysis of the $K_{S}$ parameter. Using this theoretical concept, the distribution of the stationary wave number $\left(K_{S}\right)$ is obtained for austral winters with $+\sigma$ and $-\sigma$ by Müller and Ambrizzi (2007). From these fields it is possible to determine the preferential propagation paths of the waves that reach South America. The stationary wave number $K_{s}$ indicates the regions where the Rossby wave propagation is permitted and those where it will be inhibited $\left(K_{s}=0\right)$, highlighting the importance of the jets as waveguides. An interesting feature is the difference in the longitudinal extension of $K_{s}$ for $+\sigma$ with respect to $-\sigma$, as indicated by Müller and Ambrizzi (2007, see Fig. 2e-f). In the first case this region extends towards the South American continent along the Pacific Ocean. Instead, in the $-\sigma$ basic state the $K_{s}$ extension is smaller. This result contributes to the argument that GF events occur when there is a right environment for the Rossby wave propagation such as that shown by Fig. 2a.

On the other hand, the equivalent experiment for the $-\sigma$ basic state and the forcing positioned at $170^{\circ} \mathrm{E}-15^{\circ} \mathrm{S}$ (Fig. 3a), the wave propagation trajectory generated was quite different when compared to the $+\sigma$ case (Fig. 2a). Figure 3 a shows two wave trains that depart from the forcing region; the northern one reaches the South American continent 

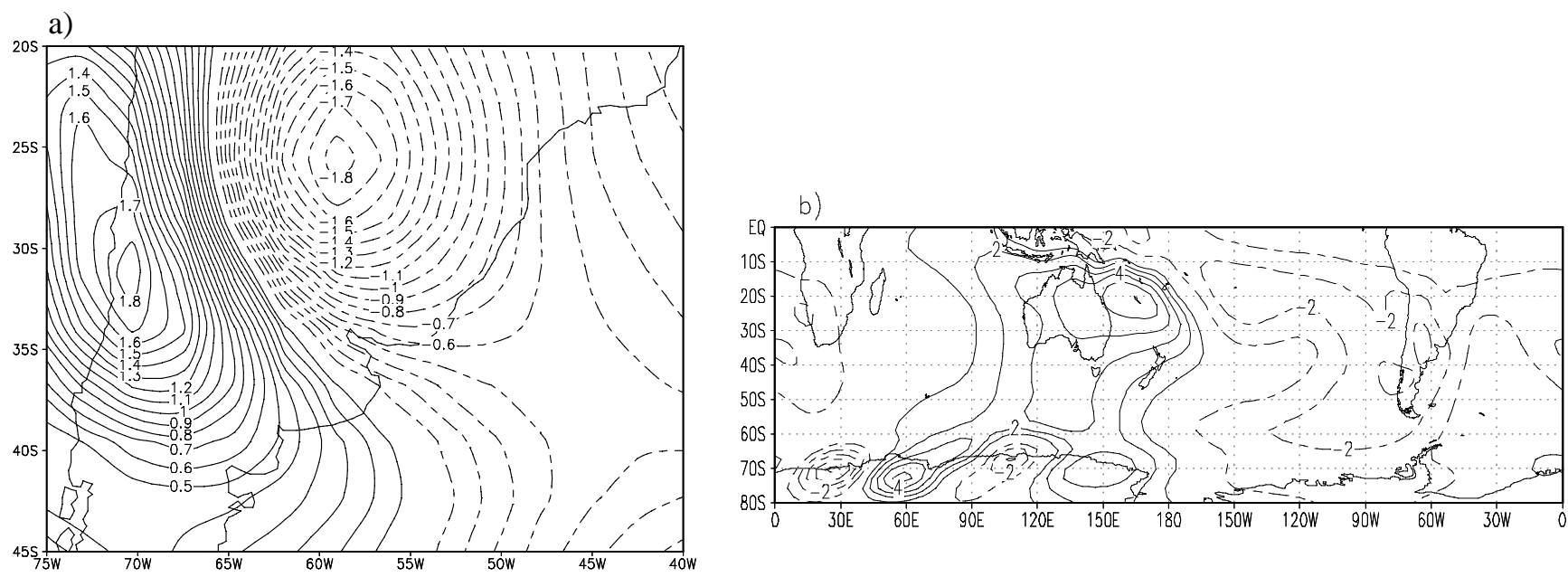

Fig. 5. Same as Fig. 4 but using $-\sigma$ basic state.

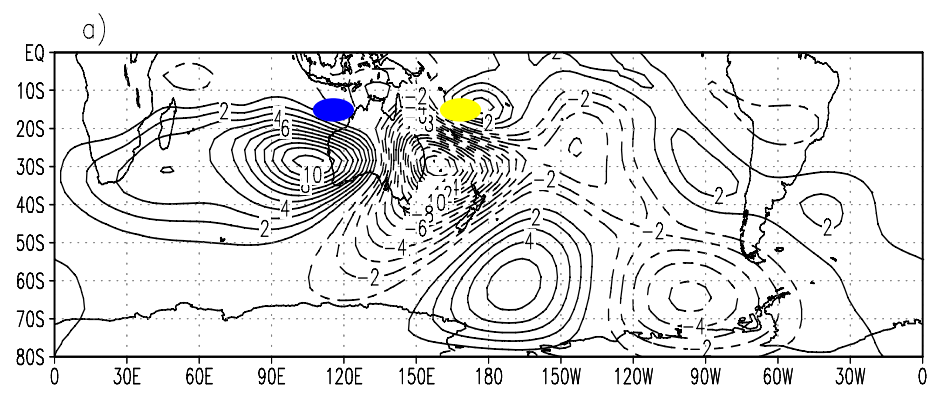

b)

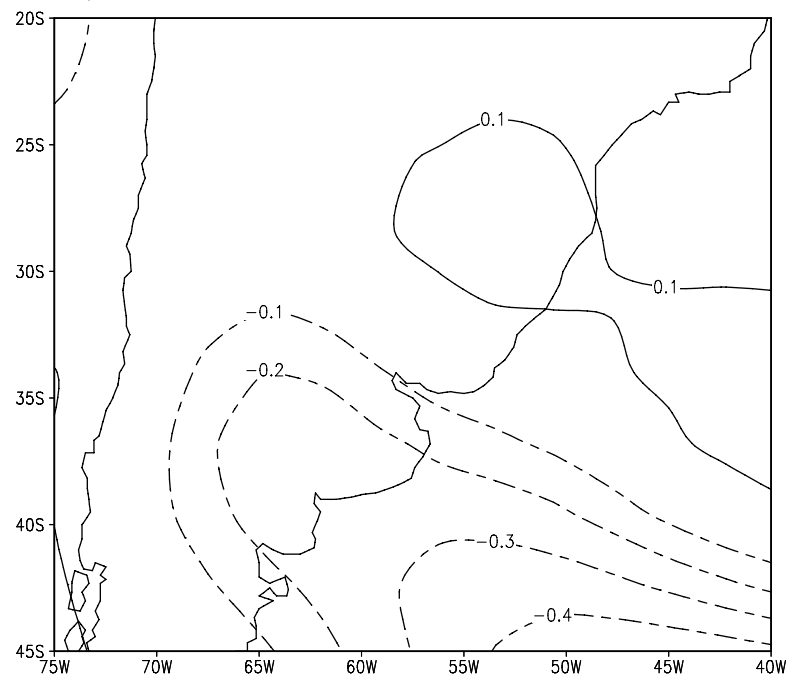

Fig. 6. (a) Stream function anomalies $\left(1 \times 10^{-6} \mathrm{~m}^{2} \mathrm{~s}^{-1}\right)$ at $250 \mathrm{hPa}$ and (b) surface temperature anomalies $\left({ }^{\circ} \mathrm{C}\right)$ on day 10 of integration, corresponding to $+\sigma$ basic state with forcing at $170^{\circ} \mathrm{E}-15^{\circ} \mathrm{S}$ and $120^{\circ} \mathrm{E}-15^{\circ} \mathrm{S}$.

at tropical latitudes, while the other wave train crosses the central Pacific and moves towards the Atlantic Ocean, where $K_{s} \neq 0$, as suggested by Müller and Ambrizzi (2007), where the meridional wind positive anomaly concentrates on the eastern side of the South American continent. At lower levels, the wind vector anomaly, depicted in Fig. 3b, shows southerly winds over the southeast of the continent, in good agreement with the upper level meridional wind anomaly (Fig. 3a).

To verify how the simulated Rossby waves favor the atmospheric circulation over the Wet Pampa region in order to create the right conditions for the extreme cold events, the surface conditions for the two basic states are analyzed. In the $+\sigma$ case, Fig. 4 a shows negative surface temperature anomalies over the Wet Pampas. This anomaly is explained by the circulation created at low levels with southern anomalous wind advection over the southern part of the continent due to the presence of an anticyclonic anomaly at low levels (Fig. 4b). This anomaly goes from the middle to high latitudes and extends from the Pacific Ocean to the southwest of South America, having an equivalent barotropic vertical extension (figure not shown), affecting a large part of Argentina. The daily and seasonal composite analysis for the GF $+\sigma$, shown by Müller et al. (2005), has also indicated the 

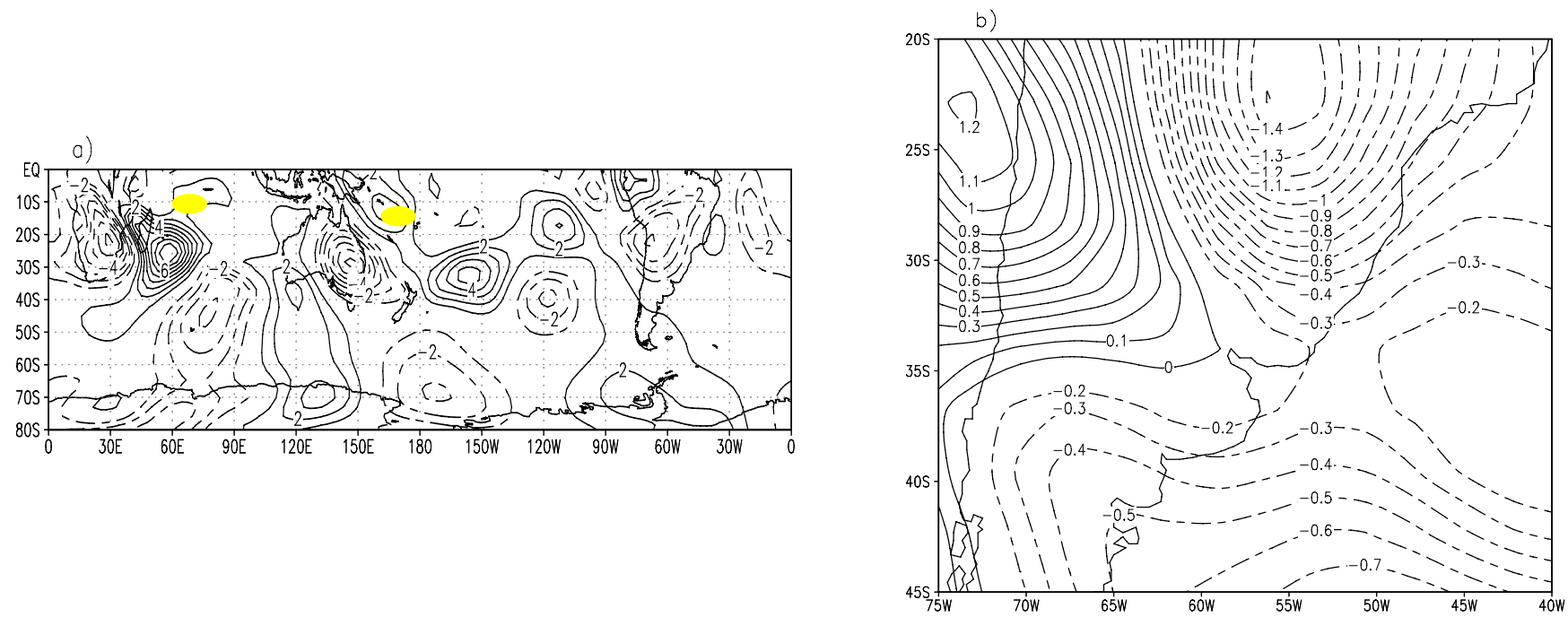

Fig. 7. (a) Meridional wind component anomalies $\left(\mathrm{ms}^{-1}\right)$ at $250 \mathrm{hPa}$ and (b) surface temperature anomalies $\left({ }^{\circ} \mathrm{C}\right)$ on day 10 of integration, corresponding to $+\sigma$ basic state experiment but using two heating sources at $170^{\circ} \mathrm{E}-15^{\circ} \mathrm{S}$ and $70^{\circ} \mathrm{E}-10^{\circ} \mathrm{S}$.

presence of an anticyclonic anomaly at low levels similar to Fig. 4b. This anomaly, as discussed by Müller et al. (2005), favors an anomalous southern flow, as observed from the low level wind fields which affect part of Argentina, particularly the Wet Pampas. The numerical simulation also showed a southerly wind anomaly over the same region (Fig. 2b). These results suggest that the extension of the region with anticyclonic anomalies may play an important role in creating the right condition for cold and dry advection from the southwest and therefore the possibility of generalized frost occurrences.

The result of the experiment with the $-\sigma$ basic state and the same heat source shows a different configuration. The surface temperature anomalies (Fig. 5a) are negative in the northeast and positive in the remaining area of interest. From Fig. 5b one can see two low level anticyclone anomalies; one over the Wet Pampas, which contributes to the generation of radiative frosts, and the other to the west of Patagonia, shifting the anomalous southerly wind towards the Atlantic (Fig. 3b). This creates a circulation with a south-southeast component and advection of maritime air and therefore a more humid situation over the Wet Pampas region. Although this pattern also causes large negative temperature anomalies something even bigger than in the $+\sigma$ case, they are not the most favorable condition for the occurrence of frosts.

\subsubsection{Further experiments}

One additional experiment performed was to use two forcings based on the two OLR anomalies observed in the western tropical Pacific during the $+\sigma$ basic state. One refers to a negative OLR anomaly situated at $170^{\circ} \mathrm{E}-15^{\circ} \mathrm{S}$ and the other to a positive at $120^{\circ} \mathrm{E}-15^{\circ} \mathrm{S}$, as shown in Fig. 1a. In the experiment these anomalies are simulated putting a heat source in the position of the first one and a "negative source" in the other one. The response to these perturbations (Fig. 6) presents a configuration similar to the PSA modes found by Mo and Higgins (1998) and referred to as PSA2, which, as mentioned in Sect. 3.1, are associated with OLR anomalies similar to those found for $+\sigma$ composites. Vera et al. (2004) associated this PSA2 pattern to a warm ENSO phase. However, as seen in Fig. 1a, the central equatorial Pacific region presents positive OLR anomaly values which are related to negative SST anomalies there (Müller et al., 2005). In the present experiment the PSA2 pattern found may be attributed to the dipole convection at $15^{\circ} \mathrm{S}$ approximately to the west of the date line.

Some previous studies (e.g. Berbery and Nogues-Paegle, 1993; Tyrrell et al., 1996) have shown that the PSA2 configuration described above is the direct result of the upper level divergent flow due to the anomalous convection that creates a strong absolute vorticity gradient across the westerlies in the Southern Hemisphere. The resulting anticyclonic vorticity tends to generate a subtropical source of Rossby waves over Australia, with eastward energy dispersion. Figure 6a shows a wave pattern extending from Australia, with an intense anticyclonic (cyclonic) anomaly on the eastern (western) side of the continent, which propagates towards the western part of the Antarctic Peninsula and then turns towards the Atlantic Ocean, with a positive stream function anomaly on the South American coast. This pattern generates an anomalous southeastern flow over Patagonia, reaching central Argentina (figure not shown). It is interesting to notice the remarkable intensity of the anticyclonic anomaly in the Pacific Ocean to the southwest of the continent and another anticyclonic anomaly situated to the northwest of the 

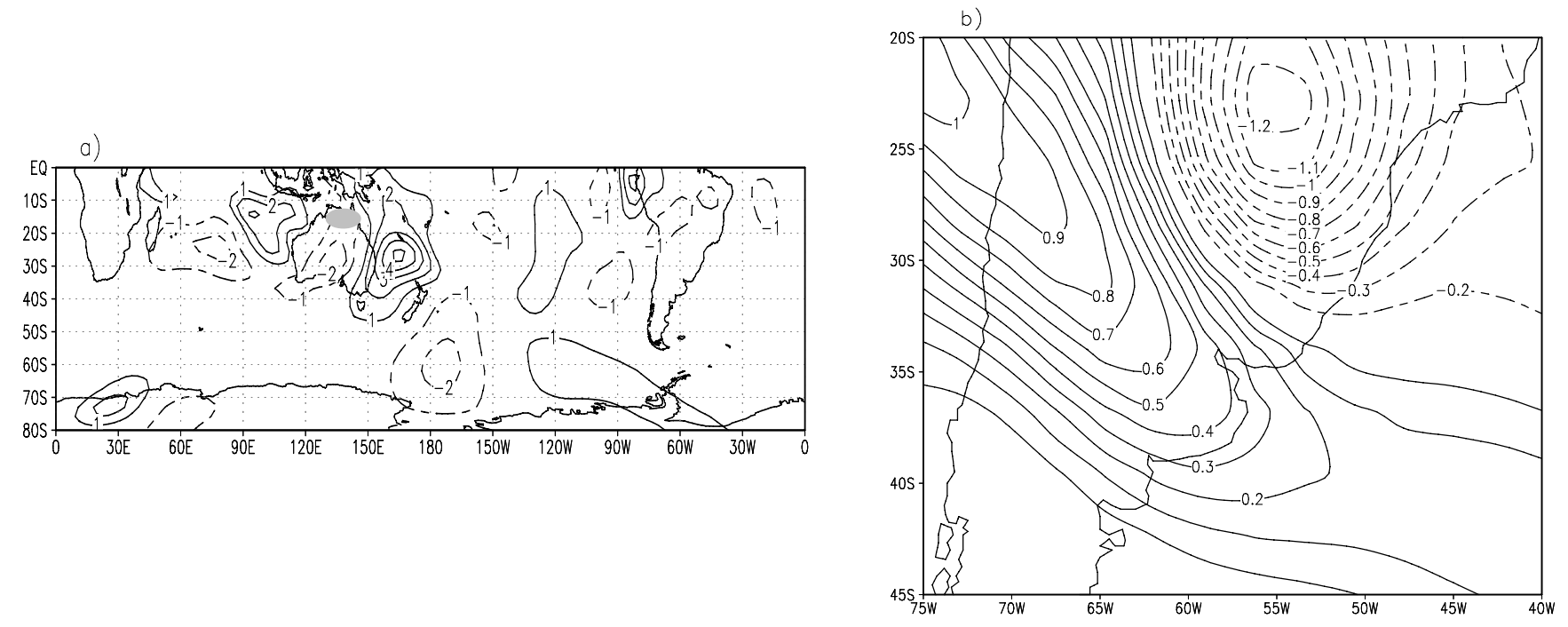

Fig. 8. (a) Meridional wind component anomalies $\left(\mathrm{ms}^{-1}\right)$ at $250 \mathrm{hPa}$ and (b) surface temperature anomalies $\left({ }^{\circ} \mathrm{C}\right)$ on day 10 of integration, corresponding to $+\sigma$ basic state experiment with forcing at $140^{\circ} \mathrm{E}-15^{\circ} \mathrm{S}$.

former one, which act to block the western flow. This configuration favors the persistence of systems over the continent and therefore the formation of frosts. Müller et al. (2005) in their observational analysis of $+\sigma$ events also found an anticyclonic anomaly blocking over the South Pacific. At low levels a weak cyclonic circulation anomaly close to the coast of Buenos Aires and an anticyclonic anomaly to the north directed the wind in the region (figure not shown). The surface temperature anomaly field reflects this disposition and shows slightly negative (positive) anomalies to the south (north) of the Wet Pampas (Fig. 6b).

The wave propagation pattern depicted in Fig. 6a is in agreement with the conclusions presented by Hoskins and Karoly (1981), who point out that a heating source situated at low latitudes can generate waves where the short ones are trapped on the equatorial side of the jet and the longer ones propagate to the east towards the Pole. Moreover, it can be proved that both wave trains found follow preferential wave propagation trajectories during the austral winter or teleconnection routes, as suggested by Ambrizzi et al. (1995).

A further experiment is performed considering two heat sources which mimic the convection observed in the tropical Pacific and Indian Oceans (see Fig. 1a). When combining the Indian Ocean source at $70^{\circ} \mathrm{E}-10^{\circ} \mathrm{S}$ with the one in the western Pacific at $170^{\circ} \mathrm{E}-15^{\circ} \mathrm{S}$, it is observed that the energy coming from the Indian Ocean propagates towards high latitudes and does not pass by the South American continent (Fig. 7a). It is verified that the lower latitude wave train has similar characteristics to the one found in the $170^{\circ} \mathrm{E}-$ $15^{\circ} \mathrm{S}$ experiment. Then, over the continent, there are no differences in the configuration shown by the meridional wind anomalies aloft with respect to the $170^{\circ} \mathrm{E}-15^{\circ} \mathrm{S}$ experiment (Fig. 2), although they are somewhat shifted southwards, which leads to an anomalous surface temperature field with a small amplitude over the Wet Pampa (Fig. 7b). The wave train which propagates along the polar jet in $+\sigma$, is not seen in the $-\sigma$ case (not shown).

An additional simulation only using a forcing at $70^{\circ} \mathrm{E}-$ $10^{\circ} \mathrm{S}$ (south central Indian Ocean) also generates a wave train that did not reach South America (figure not shown). It is suggested from the results above that despite having two or even more forcings perturbing the atmosphere, it is the basic state structure that will define the atmosphere waveguide and therefore the teleconnection pattern, as previously suggested by simple wave theory (Hoskins and Ambrizzi, 1993). Of course, we are assuming that the forcing itself does not modify the basic state in this case.

In order to verify how the wave propagation pattern is generated in the tropical region when there was no convection according to Fig. 1a, two additional experiments with basic states $+\sigma$ and $-\sigma$ were carried out. In this case the heating source was positioned at $140^{\circ} \mathrm{E}-15^{\circ} \mathrm{S}$. From the meridional wind anomalies at $250 \mathrm{hPa}$ for $+\sigma$ (Fig. 8a) there is no clear wave propagation pattern. At low levels an anticyclonic atmospheric circulation is observed to the north of the Buenos Aires province (figure not shown). This anomalous anticyclone may explain the negative and positive temperature anomalies to the north and over the Wet Pampas, respectively, as observed in Fig. 8b. This configuration is similar to the one obtained in the experiment of the forcing at $70^{\circ} \mathrm{E}-$ $10^{\circ} \mathrm{S}$ (figure not shown), where no wave trains reached the South American continent.

Although one can see some similarities among the teleconnection patterns obtained for different locations of the heating source, the pattern of the wave trains that reach South America necessary to generate a favorable condition 

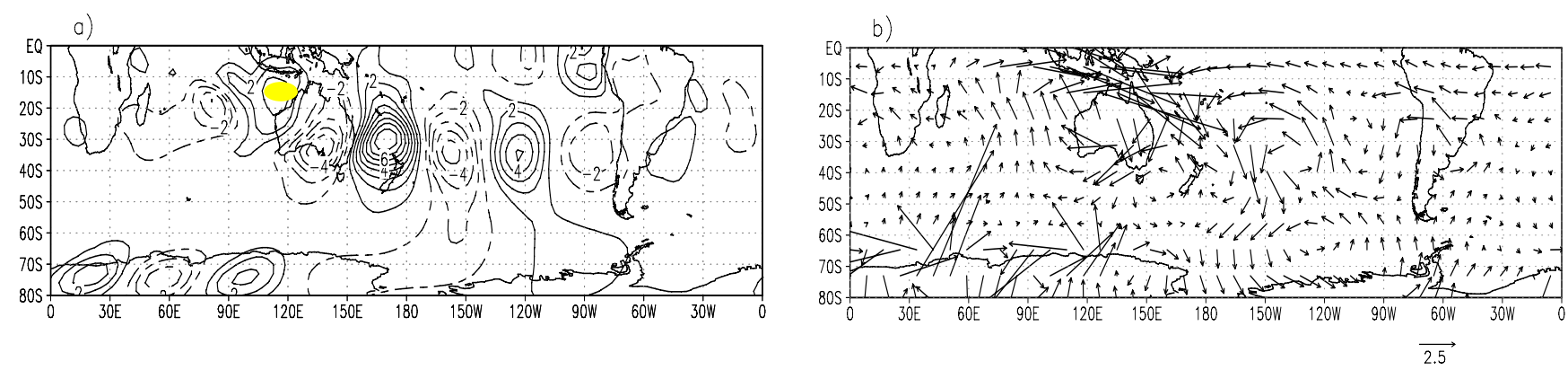

Fig. 9. (a) Meridional wind component anomalies $\left(\mathrm{ms}^{-1}\right.$ ) at $250 \mathrm{hPa}$ and (b) wind vector anomalies at $850 \mathrm{hPa}$ on day 10 of integration, corresponding to $-\sigma$ basic state experiment with forcing at $120^{\circ} \mathrm{E}-15^{\circ} \mathrm{S}$.
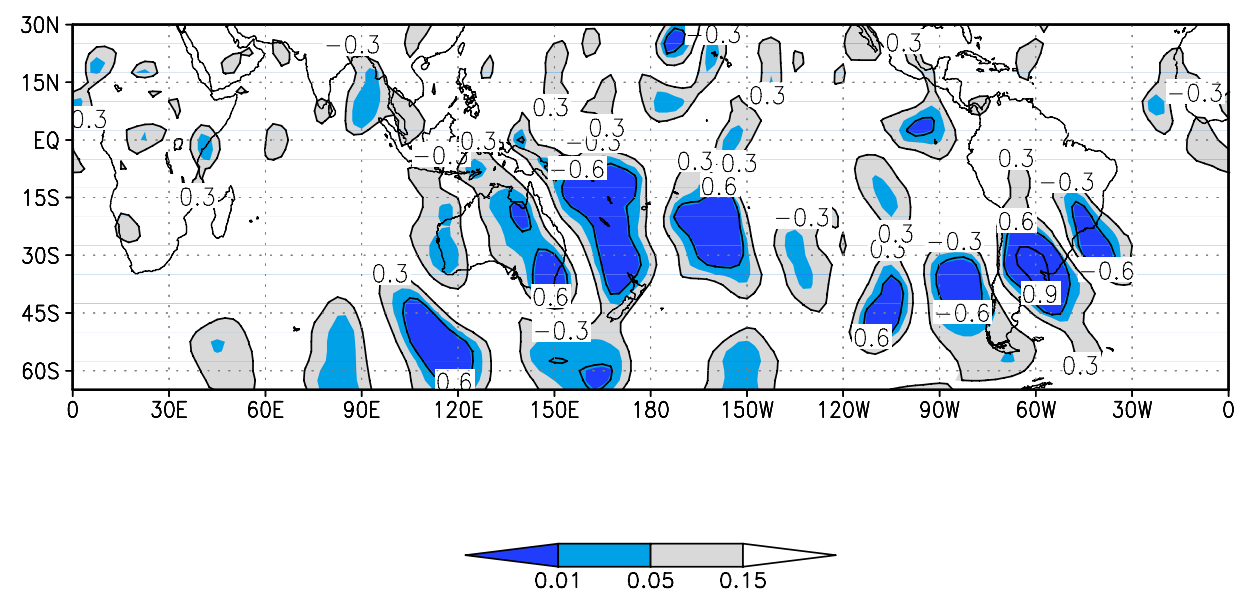

Fig. 10. Correlation fields between the averaged meridional wind over the Wet Pampa area during GF events and the global meridional wind at $250 \mathrm{hPa}$ (lag 0 ). Only significant values at the $95 \%$ level are shown and indicated by the shaded contours.

for extreme cold events on the Wet Pampas is dependent on the right position of the forcing in the $+\sigma$ basic state. On the other hand, for the $-\sigma$ basic state none of the analyzed forcing positions created a pattern that could generate an extended temperature decrease over the area of interest, not even in the case when the forcing was directly associated with the observed convection in this basic state. For instance, the simulation with the heat source at $120^{\circ} \mathrm{E}-15^{\circ} \mathrm{S}$, corresponding to the observed anomalous convection in $-\sigma$, shows a wave train following the path of the subtropical jet (Fig. 9a). The meridional wind anomalies weaken just before it reaches South America in a region of zero $K_{s}$ between $35^{\circ}$ and $40^{\circ} \mathrm{S}$ in the west of Argentina, which coincides with the main entrance region of weather systems over South America (Müller and Ambrizzi, 2007). At low levels, a northern meridional wind anomaly is observed and probably interferes with the cold air advection from the south on the lee side of the Andes (Fig. 9b). Surface temperature anomalies are negative (not shown) in the northern part of the Wet Pampas and positive in the central and southern area. The low level circulation may generate radiative frosts but without any possi- bility to become generalized once the influence of the anticyclonic anomaly is confined to a minor area inside the Wet Pampas.

\subsection{Observed analyses}

One of the main variables in the present analysis is the meridional wind which better represents the wave propagation patterns at upper levels. In order to clarify the atmospheric circulation patterns related to the Wet Pampas frost events for the $+\sigma$ basic state, a correlation analysis between the observed meridional wind at the 250 and $850 \mathrm{hPa}$ levels and the mean meridional wind over the Wet Pampa (Figs. 10 and 12), as well as the mean surface temperature (Fig. 11) was performed. The correlations were based on the GF dates depicted in the Table 1 and only lag 0 will be shown.

Figure 10 shows a wave-like pattern extending over the entire Pacific with correlation values up to 0.9 (99\% of significante level) between the global meridional wind and the mean wind at the Wet Pampas during GF days. Comparing this figure with the simulated pattern shown in Fig. 2 one can see a good agreement between the two plots where the 


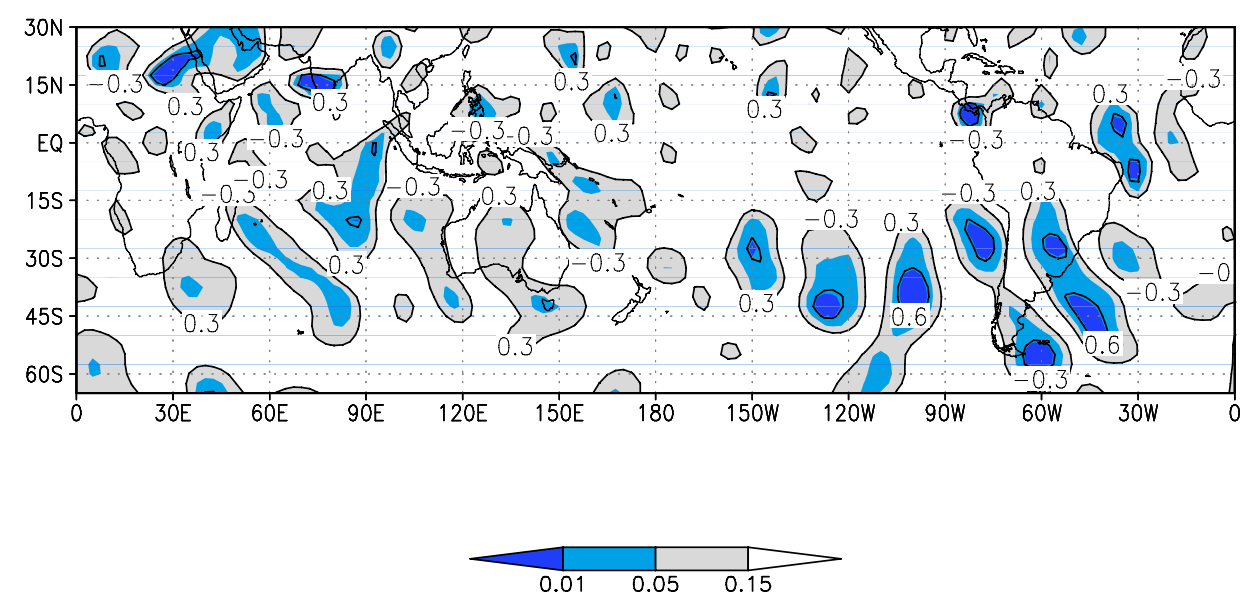

Fig. 11. Correlation fields between the average surface temperature over the Wet Pampa area during GF events and the global meridional wind at $250 \mathrm{hPa}$ (lag 0). Only significant values at the $95 \%$ level are shown and indicated by the shaded contours.

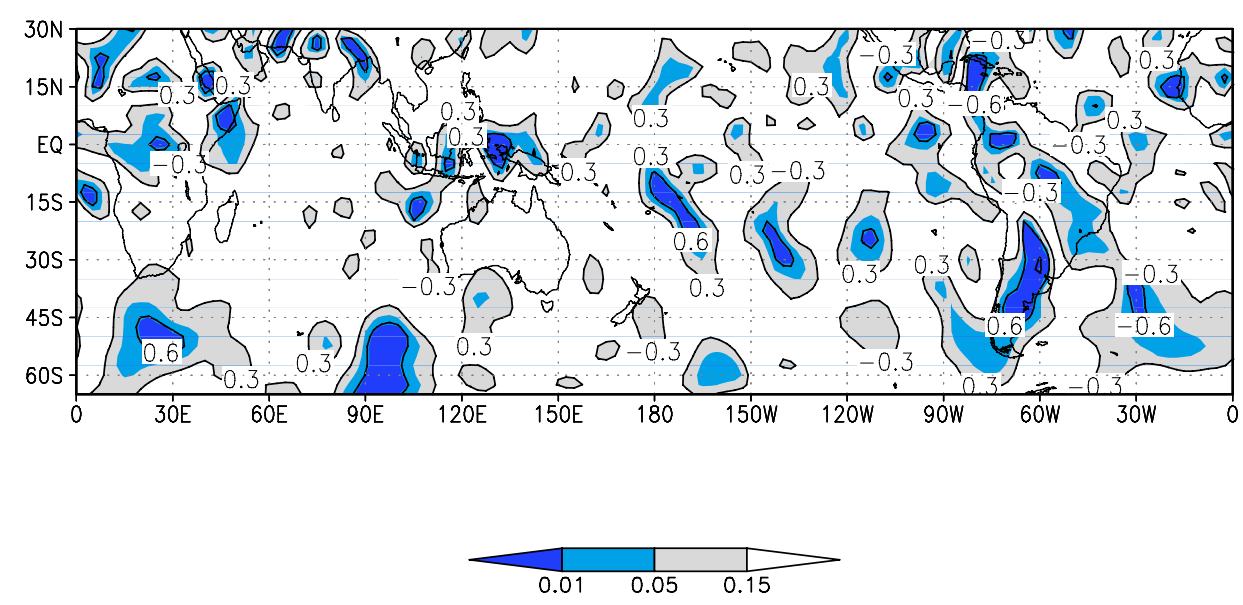

Fig. 12. Correlation fields between the average meridional wind over the Wet Pampa area during GF events and the global meridional wind at $850 \mathrm{hPa}$ (lag 0). Only significant values at the $95 \%$ level are shown and indicated by the shaded contours.

southern wind is emphasized as important to bring cold air to the preferential region of GF.

The correlation between the global meridional wind at $250 \mathrm{hPa}$ and the mean surface temperature over the Wet Pampas during GF days is shown in Fig. 11. In this case the wave-like propagation pattern shows a significant correlation (95\% level) with the southerly (northerly) wind to the south (north) of the analyzed region. The presence of a trough to the south and a ridge to the north is a common feature of GF episodes (Müller et al., 2005). This result is coherent with that shown in Fig. 4a, where the surface anomalous temperature simulated indicates negative values to the south of the Wet Pampa. These features also agree with the meridional wind anomaly at $850 \mathrm{hPa}$ simulated (Fig. 2b) and the wind correlation depicted in Fig. 12 which clearly shows a southern wind flow in this region. It should be noticed that the wind correlation in this region is 0.6 with a statistical sig- nificance of $99 \%$, suggesting that the model simulations are robust.

\section{Discussion and conclusions}

This study analyzes the role played by anomalous tropical convection during Austral winters on the occurrence of a maximum frequency of generalized frosts GF $(+\sigma)$ over the southeast South America through teleconnection patterns. The tropic-extratropic relation is investigated through numerical experiments considering basic states formed by the winters with a maximum and minimum frequency of occurrence for the extreme cold events ( $+\sigma$ and $-\sigma$, respectively).

The result of the experiment for the $+\sigma$ basic state and the heat source in the position where a significant anomalous convection was observed (Pacific Ocean) showed negative 
temperature anomalies over the whole Wet Pampas region. The atmospheric circulation field simulated favors a southerly anomalous wind component, defining a synoptic situation which causes frosts due to the advection of cold dry air from the south. The result of the experiment with a $-\sigma$ basic state and the heat source at same position, as in the previous experiment, shows a different configuration. The surface temperature anomalies are negative to the northeast and positive over the remaining area. At low levels the circulation does not produce a favorable condition for the occurrence of frosts because part of the Wet Pampa region is dominated by a south-southeast wind component bringing maritime air.

The pattern of the upper level wave train propagation is another important difference between the two simulations. The experiment with the $+\sigma$ basic state shows a Rossby wave pattern with an arc-like trajectory that initially moves towards the South Pole and then returns to the equator because of the $K_{s}=0$ constraint around $40^{\circ} \mathrm{S}$ (Müller and Ambrizzi, 2007). This wave train reaches South America in its central portion and creates a southerly wind anomaly affecting the southern part of the continent. In the $-\sigma$ case, the wave does not follow the same path and two wave trains departing from the heat source are observed. One of them propagates to the north and reaches the South American continent at tropical latitudes, while the other moves towards the Atlantic crossing the central-southwest Pacific Ocean (where $K_{s} \neq 0$, Müller and Ambrizzi, 2007) passing by the tip of South America. In general those waves that propagate at high latitudes, rapidly cross the southern part of the continent and do not usually contribute to the generation of a favor environment to the formation of GF.

In the experiments with two observed heating sources in the $+\sigma$ basic state, the energy generated by the forcing over the Indian Ocean propagated towards high latitudes, reaching South America in its most southern part and therefore having a weak impact. The wave train which propagates along the polar jet in $+\sigma$, is not seen in the $-\sigma$ case. The experiment including a positive and a negative heating source in the tropics of the Southern Hemisphere in the $+\sigma$ case shows a wave pattern configuration similar to the Mo and Higgins (1998) PSA2 mode. It has generated a wave pattern which extends from Australia towards the west of the Antarctic Peninsula, then turns towards the Atlantic with a positive stream function anomaly on the South American coast. This pattern generates an anomalous southeastern flow over Patagonia, reaching central Argentina. An intense anticyclonic anomaly in the southwest Pacific linked to another one situated in the northwest Pacific act to block the westerly flow. This configuration favors the persistence of systems over the South American continent and therefore the formation of generalized frosts.

The simulation with the heat source corresponding to anomalous convection observed in the $-\sigma$ case, shows surface temperature anomalies negative to the north of the Wet Pampas and positive in its central and southern part. The low level circulation suggests that the low temperature found is probably due to radiative frosts having little chance to become generalized. The upper level circulation shows a wave train oriented along the subtropical jet waveguide. The meridional wind anomalies weaken just before it reaches South America, again where the stationary wave number is equal to zero (Müller and Ambrizzi, 2007), and in the same place at low levels, a northern meridional wind anomaly is observed and it probably interferes with the cold air advection from the south on the lee side of the Andes.

Finally, the experiment with the heating source which does not correspond to the anomalous convection observed in both basic states, generated a wave pattern that did not create a favorable condition for frost formation. In the $-\sigma$ basic state, none of the forcing positions tested resulted in a pattern which contributed to an extended temperature descent over the Wet Pampa. Instead, in the $+\sigma$ case, the position of the forcing seems to be very important; once when it is moved from the observational convection position the response did not lead to a surface temperature decrease and consequently generalized frosts. The numerical results presented here pointed out that the wave trains excited by anomalous convection situated in a specific place may propagate across the Pacific Ocean and reach South America in a correct phase, creating local favorable conditions for the occurrence of generalized frosts in the Wet Pampas. However, the anomalous convection by itself is not enough where the response also depends of the basic state configuration. This has been demonstrated by placing the forcing over the region of maximum anomalous convection for $+\sigma$ and $-\sigma$ cases and the response was very different in each case.

Correlation analysis between the global meridional wind at upper and lower levels and the average meridional wind and surface temperature over an area of the Wet Pampa region during GF days, suggested that the results obtained by the model simulation are quite robust. In particular, the southerly wind east of the Andes responsible for bringing cold and dry air to the region of interest is well correlated.

In summary, the results presented here suggest that stationary Rossby waves may be the main mechanism linking anomalous tropical convection with the extreme cold events in the Wet Pampas. The association of tropical convection and a specific basic state can generate the right environment to guide the Rossby waves trigged by the tropical forcing towards the South America. Depending on the phase that the waves enter in the South American continent, they can favor the low level atmosphere circulation, in order to create an intense southerly cold air advection and therefore a generalize frost in the region. This study contributes to a better understanding of these systems and it may help their forecast.

Acknowledgements. G. V. Müller thanks CNPq for the postdoctoral scholarship (No. 152039/2004-0). TA was also supported by CNPq (3003401/2005-3), CAPES and FAPESP. This paper is part of the first author's PhD Thesis at the University of Buenos Aires. 
Topical Editor F. D'Andrea and the authors thank two anonymous referees for their help in evaluating this paper.

\section{References}

Ambrizzi, T., Hoskins, B. J., and Hsu, H. H.: Rossby wave propagation and teleconnection patterns in the austral winter, J. Atmos. Sci., 52, 3661-3672, 1995.

Ambrizzi, T. and Hoskins, B. J.: Stationary Rossby wave propagation in a baroclinic atmosphere, Q. J. Roy. Meteorol. Soc., 123, 919-928, 1997.

Antico, P. L.: Monthly mean subtropical jet extremes over South America during Austral winter, Ph.D. Thesis, Department of Atmospheric Sciences, University of Buenos Aires, Argentina, 2003 (in Spanish).

Berbery, E. H. and Nogues-Paegle, J.: Intraseasonal interactions between the tropics and extratropics in the Southern Hemisphere, J. Atmos. Sci., 50, 1950-1965, 1993.

Cavalcanti, I. and Kayano, M. T.: High frequency patterns of the atmospheric circulation over the Southern Hemisphere and South American, Meteor. Atmos. Phys., 69, 179-193, 1999.

Garreaud, R. D.: Cold air incursions over subtropical South America: Mean Structure and Dynamics, Mon. Weather Rev., 128, 2544-2559, 2000.

Hoskins, B. J. and Karoly, D. J.: The steady linear responses of a spherical atmosphere to thermal and orographic forcing, J. Atmos. Sci., 38, 1179-1196, 1981.

Hoskins, B. J. and Ambrizzi, T.: Rossby wave propragation on a realistic longitudinaly varying flow, J. Atmos. Sci., 50(12), 16611671, 1993.

Jin, F.-F. and Hoskins, B. J.: The direct response to tropical heating in a baroclinic atmosphere, J. Atmos. Sci., 52, 307-319, 1995.

Liebmann, B. and Smith, C. A.: Description of a complete (interpolated) outgoing longwave radiation dataset, B. Am. Meteorol. Soc., 77, 1275-1277, 1996.

Marengo, J. A., Cornejo, A., Satyamurty, P., Nobre, C., and Sea, W.: Cold surges in tropical and extratropical South America: The strong event in June 1994, Mon. Weather Rev., 125, 2759-2786, 1997.
Marengo, J. A., Ambrizzi, T., Kiladis, G., and Liebmann, B.: Upper-air wave trains over the Pacific Ocean and wintertime cold surges in tropical-subtropical South America leading to freezes in Southern and Southeastern Brazil, Theor. Appl. Climat., 74, 243-247, 2002.

Mo, K. C. and Higgins, R. W.: The Pacific-South American modes and tropical convection during the Southern Hemisphere Winter, Mon. Weather Rev., 126, 1581-1596, 1998.

Müller, G. V., Nuñez, M. N., and Seluchi, M. E.: Relationship between ENSO cycles and frosts events within the Wet Pampas region, Int. J. Climatol., 20, 1619-1637, 2000.

Müller, G. V., Ambrizzi, T., and Núñez, M. N.: Mean atmospheric circulation leading to generalized frosts in Central Southern South America, Theor. Appl. Climatol., 82, 95-112, 2005.

Müller, G. V.: Variabilidad Interanual de las Heladas en la Pampa Húmeda, Revista Brasilera de Meteorología, 21, 135-141, 2006.

Müller, G. V. and Ambrizzi, T.: Rossby wave propagation and its relationship with severe frosts over South America, Clivar Exchanges, 11, 18-20, 2006.

Müller, G. V. and Berri, G. J.: Atmospheric Circulation Associated with Persistent Generalized Frosts in Central-Southern South America, Mon. Weather Rev., 135(4), 1268-1289, 2007.

Müller, G. V.: Patterns Leading to Extreme Events in Argentina: Partial and Generalized Frosts, Int. J. Climatol., 27(10), 13731387, 2007.

Müller, G. V. and Ambrizzi, T.: Teleconnection Patterns and Rossby Wave Propagation Associated to Generalized Frosts over Southern South America, Clim. Dynam., 29(6), 633-645, 2007.

Nogues-Paegle, J. and Mo, K.: Transient response of the Southern Hemisphere subtropical jet to tropical forcing, J. Atmos. Sci., 45, 1493-1508, 1988.

Sardeshmukh, P. D. and Hoskins, B. J.: The generation of global rotational flow by steady idealized tropical divergence, J. Atmos. Sci., 45, 1228-1251, 1988.

Tyrrell, G. C., Karoly, D. J., and McBride, J. L.: Links between tropical convection and variations of the extratropical circulation during TOGA-COARE, J. Atmos. Sci., 53, 2735-2748, 1996.

Vera, C., Silvestri, G., Barros, V., and Carril, A.: Differences in El Niño Response over the Southern Hemisphere, J. Climate, 17, 1741-1753, 2004. 